\title{
Effects of Biochar on Ca, Mg and B Uptake of Peach Seedlings
}

\author{
Jing Sun¹, Jiaxi Han², Yingying Huang², Qianhe Jing², Aihui Li² and Lijin Lin ${ }^{1 *}$ \\ ${ }^{1}$ Institute of Pomology and Olericulture, Sichuan Agricultural University, Chengdu, Sichuan, 611130, China \\ ${ }^{2}$ College of Horticulture, Sichuan Agricultural University, Chengdu, Sichuan, 611130, China
}

\begin{abstract}
A pot experiment was conducted to study the effects of different biochar types [addition of rape straw biochar (RB), addition of paddy straw biochar (PB), addition of wheat straw biochar (WB) and addition of corn straw biochar (MB)] on the absorption of $\mathrm{Ca}, \mathrm{Mg}$ and $\mathrm{B}$ in peach seedlings. The result showed that compared to the control, all treatments added with biochar significantly decreased the $\mathrm{Ca}$ content in roots in peach seedlings. The Ca content in stems and leaves under the treatment of $\mathrm{RB}$ and $\mathrm{PB}$ in peach seedlings was higher than the control. The Mg content in roots and stems under the treatment of PB in peach seedlings was higher than the control. The Mg content in leaves in peach seedlings of all treatments added with biochar was lower than the control. The B content in roots, stems and leaves under the treatment of $\mathrm{PB}, \mathrm{WB}$ and $\mathrm{MB}$ in peach seedlings was higher than the control and the $\mathrm{B}$ content under the treatment of $\mathrm{PB}$ was at a higher level. Therefore, the treatment of PB was beneficial to the absorption of trace elements in peach seedlings.
\end{abstract}

\section{Introduction}

Biochar is a fine-grained and porous carbon material obtained by pyrolysis of organic materials such as crop straw, sawdust and animal manure under hypoxic or anaerobic conditions [1]. Many studies at home and abroad have shown that biochar has broad application prospects in improving soil physical and chemical properties and increasing crop yield [2]. The study shows that biochar can increase soil water holding capacity in the field, which is conducive to plant growth and soil nutrient conservation [3]. And the yield of rice and the number of spikelets per spike, grain number per panicle and seed setting rate are increased by treated with biochar. The average yield increases by $25.28 \%$ compared with the control [4]. Biochar could significantly reduce the leaching loss of soil phosphorus, promote plant uptake and growth of phosphorus, and improve the bioavailability of soil phosphorus [5-7]. The application of biochar in tropical and subtropical areas showes that the application of biochar not only increases the yield of soybean and maize, but also significantly increases the content in $\mathrm{Mg}$ and $\mathrm{Ca}$ in plants [8]. In this experiment, peach seedlings was used as the research object to study the effect of biochar on absorption of $\mathrm{Ca}$, $\mathrm{Mg}$ and $\mathrm{B}$ in peach seedlings after applying four different straw biochar, so as to select the biochar which is beneficial to the absorption of trace elements in peach seedlings.

\section{Materials and methods}

\section{$2.1 \quad$ Materials}

Peach seeds were purchased from a market in Chengdu, Sichuan, China. Non-polluted soil was collected from the Chengdu campus of Sichuan Agricultural University $\left(30^{\circ} 42^{\prime} \mathrm{N}, 103^{\circ} 51^{\prime} \mathrm{E}\right)$ in Chengdu, Sichuan, China. The basic soil properties were as follows: $\mathrm{pH}, 7.71$; organic matter content, $15.29 \mathrm{~g} / \mathrm{kg}$; alkaline nitrogen content, $87.99 \mathrm{mg} / \mathrm{kg}$; available phosphorus content, $55.77 \mathrm{mg} / \mathrm{kg}$; and available potassium content, $41.96 \mathrm{mg} / \mathrm{kg}$. The basic physical and chemical properties of the soil were based on references [9]. The rape straw, paddy straw, wheat straw and corn straw were collected in farmland around Sichuan Agricultural University. The straw was dried, cut and put into the muffle furnace, and carbonized at 500 degrees for two hours to produce biochar.

\subsection{Experimental design}

The Experiment was conducted in a greenhouse at the Chengdu campus of Sichuan Agricultural University from April to June 2019. In April 2019, peach seeds were sown in perlite while watering them in time to keep them moist. In April 2019, the soil was air-dried, ground and passed through a $5-\mathrm{mm}$ sieve and each plastic pot (15 cm high, $18 \mathrm{~cm}$ in diameter) was filled with $3 \mathrm{~kg}$ of ground soil. There were five treatments in the experiment, including addition of rape straw biochar (RB), addition of paddy straw biochar (PB), addition of wheat straw biochar (WB), addition of corn straw biochar (MB) and no addition ( $\mathrm{CK})$. The proportion of adding biochar to soil in each pot was $10 \mathrm{~g} / \mathrm{kg}$, and it was blended. All pots were watered every day to keep the soil moist. In April 2019, three uniformly growing seedlings until the seedlings reached a height of $10 \mathrm{~cm}$ (with about seven true leaves) were transplanted into the previously

\footnotetext{
*Corresponding author's e-mail: 1lj800924@qq.com
} 
prepared plastic pots. All pots were watered every day to keep soil moisture at $80 \%$. Each treatment was repeated three times, completely randomized block arrangement until the plants were harvested. After 1 month, the roots, stem, and leaves of each plant were separately harvested, washed with tap water, and rinsed three times with deionized water. The plant materials were blanched at $110{ }^{\circ} \mathrm{C}$ for $15 \mathrm{~min}$, dried at $75{ }^{\circ} \mathrm{C}$ until reaching a constant weight, and weighed, and crushed, which was used to determine the $\mathrm{Ca}, \mathrm{Mg}$ and $\mathrm{B}$ content in various parts of peach seedlings [10].

\subsection{Statistical analyses}

Statistical analysis was carried out by using SPSS 18.0 statistical software. The data were analyzed by one-way ANOVA, with the least significant difference at the 5\% confidence level.

\section{Results and discussion}

\subsection{Effects of biochar on absorption of $\mathrm{Ca}$ in peach seedlings}

Table 1. Effects of biochar on absorption of $\mathrm{Ca}$ in peach seedlings

\begin{tabular}{cccc}
\hline Treatments & $\begin{array}{c}\text { Roots } \\
(\mathrm{mg} / \mathrm{g})\end{array}$ & $\begin{array}{c}\text { Stems } \\
(\mathrm{mg} / \mathrm{g})\end{array}$ & $\begin{array}{c}\text { Leaves } \\
(\mathrm{mg} / \mathrm{g})\end{array}$ \\
\hline CK & $12.67 \pm 0.45 \mathrm{a}$ & $9.49 \pm 0.49 \mathrm{~d}$ & $17.01 \pm 1.03 \mathrm{c}$ \\
RB & $10.55 \pm 0.66 \mathrm{~b}$ & $15.94 \pm 0.90 \mathrm{a}$ & $24.14 \pm 2.08 \mathrm{~b}$ \\
PB & $11.97 \pm 0.76 \mathrm{ab}$ & $13.38 \pm 0.90 \mathrm{~b}$ & $30.26 \pm 1.23 \mathrm{a}$ \\
WB & $10.63 \pm 0.93 \mathrm{~b}$ & $8.16 \pm 0.38 \mathrm{~d}$ & $18.86 \pm 1.52 \mathrm{c}$ \\
MB & $11.95 \pm 0.24 \mathrm{ab}$ & $11.58 \pm 0.08 \mathrm{c}$ & $16.22 \pm 0.22 \mathrm{c}$
\end{tabular}

Value are means \pm standard errors. Means with the same letter within each column are not significantly different at $p<0.05$. RB $=$ addition of rape straw biochar, $\mathrm{PB}=$ addition of paddy straw biochar, $\mathrm{WB}=$ addition of wheat straw biochar, $\mathrm{MB}=$ addition of corn straw biochar.

Compared to the control, all treatments added with biochar significantly decreased the Ca content in roots in peach seedlings and the $\mathrm{Ca}$ content in roots in peach seedlings were $16.73 \%, 5.85 \%, 16.1 \%$ and $6.03 \%$, respectively, lower than the control (Table 1). The $\mathrm{Ca}$ content in stems in peach seedlings was significant difference between the treatment of adding biochar and the control except for the treatment of WB. The Ca content in stems in peach seedlings increased by $67.97 \%$, $40.99 \%$ and $22.02 \%$ under the treatment of RB, PB and MB compared with the control, respectively. The Ca content in leaves in peach seedlings increased by $41.92 \%$, and $77.90 \%$ under the treatment of RB and PB compared with the control, respectively.

\subsection{Effects of biochar on absorption of $\mathrm{Mg}$ in peach seedlings}

The $\mathrm{Mg}$ content in roots, stems and leaves of peach seedlings all treatments added with biochar was significant difference compared with control (Table 2). Compared to the control, all treatments added with biochar significantly increased the $\mathrm{Mg}$ content in roots in peach seedlings and the $\mathrm{Mg}$ content in roots in peach seedlings were $8.87 \%, 35.17 \%, 33.18 \%$ and $108.41 \%$, respectively, higher than the control. The $\mathrm{Mg}$ content in stems in peach seedlings increased by $8.14 \%$ under the treatment of PB compared with the control. On the contrary, the $\mathrm{Mg}$ content in stems in peach seedlings decreased by $12.68 \%, 32.62 \%$ and $17.6 \%$ under the treatment of RB, WB and MB compared with the control, respectively. The $\mathrm{Mg}$ content in leaves in peach seedlings of all treatments added with biochar was lower than control and the $\mathrm{Mg}$ content in leaves in peach seedlings decreased by $38 \%, 73.3 \%, 31.49 \%$ and $30.27 \%$ under the treatment of RB, PB, WB and MB compared with the control, respectively.

Table 2. Effects of biochar on absorption of $\mathrm{Mg}$ in peach seedlings

\begin{tabular}{cccc}
\hline Treatments & $\begin{array}{c}\text { Roots } \\
(\mathrm{mg} / \mathrm{g})\end{array}$ & $\begin{array}{c}\text { Stems } \\
(\mathrm{mg} / \mathrm{g})\end{array}$ & $\begin{array}{c}\text { Leaves } \\
(\mathrm{mg} / \mathrm{g})\end{array}$ \\
\hline CK & $6.54 \pm 0.38 \mathrm{c}$ & $13.64 \pm 0.31 \mathrm{~b}$ & $30.26 \pm 0.94 \mathrm{a}$ \\
RB & $7.12 \pm 0.10 \mathrm{c}$ & $11.91 \pm 0.74 \mathrm{c}$ & $18.76 \pm 0.66 \mathrm{c}$ \\
PB & $8.84 \pm 0.26 \mathrm{~b}$ & $14.75 \pm 0.04 \mathrm{a}$ & $8.08 \pm 0.39 \mathrm{~d}$ \\
WB & $8.71 \pm 0.89 \mathrm{~b}$ & $9.19 \pm 0.46 \mathrm{~d}$ & $20.73 \pm 0.61 \mathrm{bc}$ \\
MB & $13.63 \pm 0.26 \mathrm{a}$ & $11.24 \pm 0.22 \mathrm{c}$ & $21.10 \pm 1.29 \mathrm{~b}$ \\
\hline
\end{tabular}

Value are means \pm standard errors. Means with the same letter within each column are not significantly different at $p<0.05 . \mathrm{RB}=$ addition of rape straw biochar, $\mathrm{PB}=$ addition of paddy straw biochar, $\mathrm{WB}=$ addition of wheat straw biochar, $\mathrm{MB}=\mathrm{addition}$ of corn straw biochar. 


\subsection{Effects of biochar on absorption of $B$ in peach seedlings}

Table 3. Effects of biochar on absorption of B in peach seedlings

\begin{tabular}{cccc}
\hline Treatments & $\begin{array}{l}\text { Roots } \\
(\mu \mathrm{g} / \mathrm{g})\end{array}$ & $\begin{array}{c}\text { Stems } \\
(\mu \mathrm{g} / \mathrm{g})\end{array}$ & $\begin{array}{c}\text { Leaves } \\
(\mu \mathrm{g} / \mathrm{g})\end{array}$ \\
\hline CK & $52.97 \pm 1.20 \mathrm{c}$ & $57.66 \pm 2.37 \mathrm{c}$ & $57.37 \pm 1.74 \mathrm{c}$ \\
RB & $52.70 \pm 1.55 \mathrm{c}$ & $53.36 \pm 2.41 \mathrm{c}$ & $49.82 \pm 3.00 \mathrm{~d}$ \\
PB & $55.27 \pm 1.72 \mathrm{bc}$ & $79.12 \pm 2.24 \mathrm{a}$ & $89.37 \pm 2.04 \mathrm{a}$ \\
WB & $59.72 \pm 1.52 \mathrm{a}$ & $59.68 \pm 1.41 \mathrm{c}$ & $62.34 \pm 1.92 \mathrm{bc}$ \\
MB & $57.84 \pm 1.28 \mathrm{ab}$ & $72.22 \pm 3.78 \mathrm{~b}$ & $67.04 \pm 1.30 \mathrm{~b}$ \\
\hline
\end{tabular}

Value are means \pm standard errors. Means with the same letter within each column are not significantly different at $p<0.05$. RB $=$ addition of rape straw biochar, $\mathrm{PB}=$ addition of paddy straw biochar, $\mathrm{WB}=$ addition of wheat straw biochar, $\mathrm{MB}=\mathrm{addition}$ of corn straw biochar.

The $\mathrm{B}$ content in roots, stems and leaves in peach seedlings under the treatment of RB was all lower than the control (Table 3). On the contrary, the B content in roots, stems and leaves in peach seedlings under the other treatments added with biochar was higher than the control. The $\mathrm{B}$ content in roots in peach seedlings increased by $12.94 \%$, and $9.2 \%$ under the treatment of WB and MB compared with the control, respectively. The $\mathrm{B}$ content in stems in peach seedlings of the treatment of $\mathrm{PB}$ and $\mathrm{MB}$ was higher than the control and the $\mathrm{B}$ content in stems in peach seedlings increased by $37.22 \%$ and $25.25 \%$ under the treatment of $\mathrm{PB}$ and $\mathrm{MB}$ compared with the control, respectively. Compared to the control, the treatment of $\mathrm{PB}, \mathrm{WB}$ and $\mathrm{MB}$ significantly increased the $\mathrm{B}$ content in leaves in peach seedlings and the B content in leaves in peach seedlings were $8.87 \%$, $35.17 \%, 33.18 \%$ and $108.41 \%$, respectively, higher than the control.

\section{Conclusions}

According to the experiment, the $\mathrm{Ca}$ content in roots in peach seedlings of all treatments added with biochar was lower than the control. The $\mathrm{Ca}$ content in stems and leaves under the treatment of $\mathrm{RB}$ and $\mathrm{PB}$ in peach seedlings was higher than the control. The Mg content in roots and stems under the treatment of $\mathrm{PB}$ in peach seedlings was higher than the control. However, the $\mathrm{Mg}$ content in leaves in peach seedlings of all treatments added with biochar was lower than the control. The B content in roots, stems and leaves under the treatment of $\mathrm{PB}, \mathrm{WB}$ and $\mathrm{MB}$ in peach seedlings was higher than the control and the $\mathrm{B}$ content in treatment of $\mathrm{PB}$ was at a higher level. Therefore, the treatment of $\mathrm{PB}$ was beneficial to the absorption of trace elements in peach seedlings.

\section{Acknowledgments}

This work was financially supported by the National Key Research and Development Plan of China (2018YFD0201400).

\section{References}

1. Bu, X.L., Xue, J.H. (2014) Research progress on the effects of biochar on soil habitat and plant Growth. J. Ecol. \& Environ., 23: 535-540.

2. Ling, H.W., Li, X.Y., Zhou, Y.H., Kong, Q. (2019) Effects of different biochar mixtures on soil nutrients and broad bean growth. Jiangsu Agric. Sci., 47: 110-112.

3. Wu, W., Li, X.Q., Zhou, Y.C., Li, Y.L., Huang, Y.M., Li, Y., Zhang, L.K., Wang, Q., Cheng, J.Z. (2017) Impact of corn straw biochar on water holding capacity of the yellow soil in Guizhou Province, China. Earth \& Environ., 45: 675-680.

4. Zhang, W.M., Meng, j., Wan, J.Y., Fan, S.X., Chen, W.F. (2013) Effect of biochar on root morphological and physiological characteristics and yield in rice. Acta. Agro. Sin., 39: 1445-1451.

5. Wu, W.J., Xy, Y.L., Xing, S.L., Ma, F.F., Chen, N.Y., Ma, Y.H. (2018) Effect of biochar on soil nitrogen and phosphorus transformation and loss. J. Agro., 8: 20-26.

6. Ge, S.F., Zhou, L., Men, Y.G., Li, H.N., Wei, S.C., Jiang, Y.M. (2013) Effect of carbon application on nitrogen and phosphorus leaching in apple orchard soil. J. Soil Water Conserv., 27: 31-35.

7. Yu, W.M., Shi, Y,F., Wang, R.P., Liao, X.R., Liang, J.W., Wang, X.J. (2018) The Effects of modified biochar on the growth and phosphorus absorption of Brassica chinensis L.. J. Ecol. \& Environ., 27: 18781882.

8. Lehmann, J., Weigl, D., Peter, I., Droppelmann, K., Gebauer, G., Goldbach, H., Zech, W. (1999) Nutrient interactions of alley cropped Sorghum bicolor and Acacia saligna in a runoff irrigation system in Northern Kenya. Plant Soil, 210: 249-262.

9. Bao, S.D. (2000) Agrochemical Soil analysis. China Agriculture Press, Beijing.

10. Zhang, Y. (2011) Soil, water and plant physical and chemical analysis course. Chinese Forestry Press, Beijing. 